\title{
MÉTODOS DE REALIZAGIÓN ESPIRITUAL EN EL SUFISMO
}

\author{
Alberto Ventura (Università della Calabria)
}

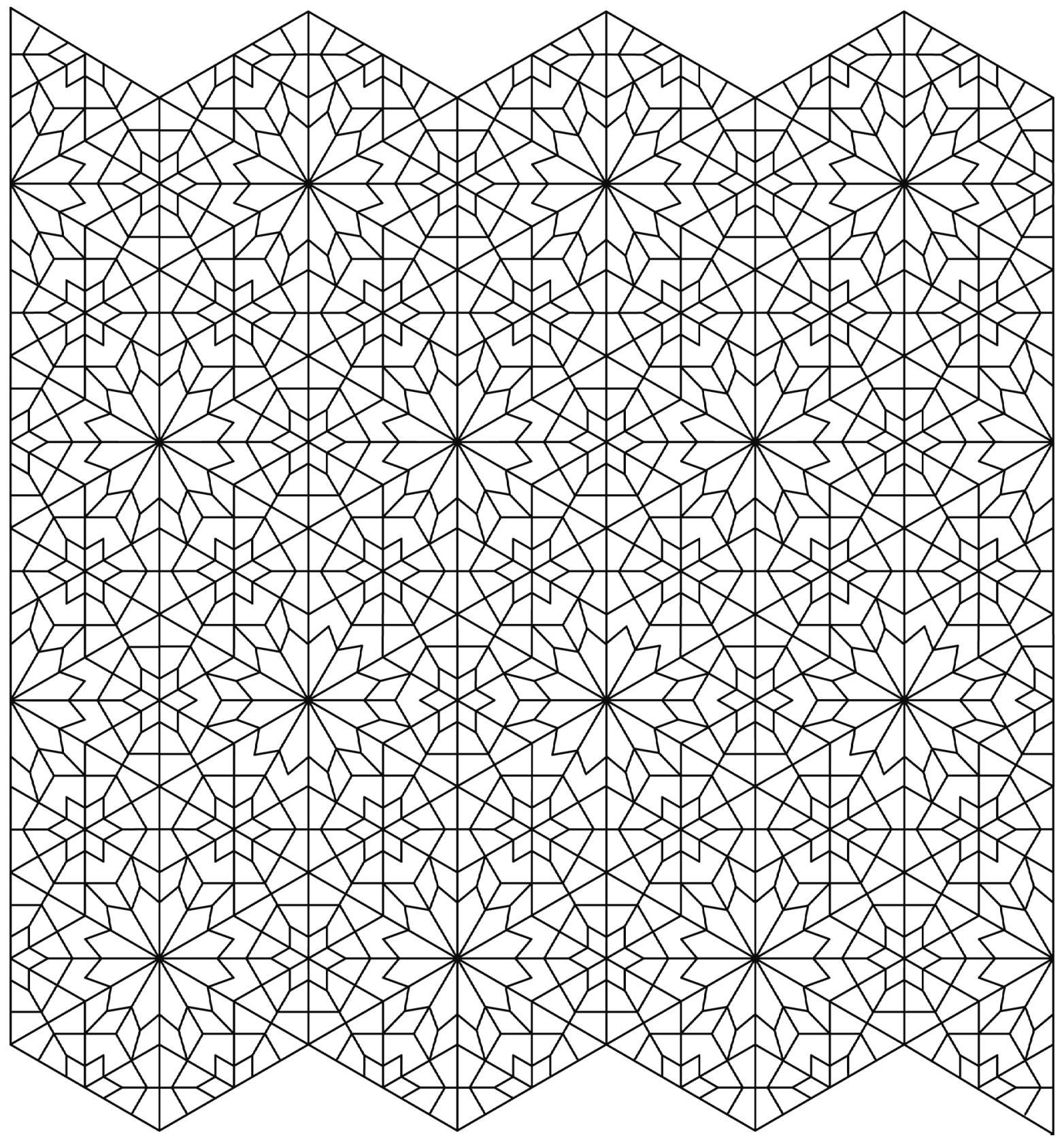


Resumen: A diferencia de otras formas de conocimiento que conforman las disciplinas del saber de la tradición islámica, el sufismo no se limita a la especulación teórica, sino que comprende una serie de métodos rigurosos de realización interior, en tanto que vía iniciática. El más conocido de estos métodos es el dikr, la repetición o invocación de los Nombres Divinos, práctica que puede ir acompañada de una diversidad de ejercicios contemplativos, que pueden incluir el control de la respiración, posturas corporales y la meditación por medio de visualizaciones. El objetivo de este artículo es explorar con cierto grado de minuciosidad los aspectos más relevantes de estas prácticas, y muy particularmente la noción de murāqaba o contemplación, considerada por algunas escuelas de sufismo como la forma más directa y eficaz de realizar el conocimiento de lo divino.

Palabras clave: $\underline{d} i k r$, silsilat al-dahab, mušāhada, suspensión de la respiración, murāqaba, transmisión iniciática.

\begin{abstract}
In contrast to the array of intellectual disciplines within traditional Islam, the Sufi path of knowledge is not limited to mere theoretical speculation. Rather, it entails a series of rigorous methods of inner realisation as part of its iniciatic teachings. Among these, the most effective and known methods is $\underline{d i k r}$, the invocation or remembrance of the Divine Names, a method of spiritual realisation that often goes hand in hand with various meditative practices that include breath control, specific body postures and visualizations. This article aims at exploring, with a certain degree of detail, the most relevant aspects pertaining to these practices, and in particular the notion of murāqaba - or contemplation - deemed by some school of Sufism as the most direct and effective way to reach the Divine.
\end{abstract}

Keywords: $\underline{d i k r}$, silsilat al-dahab, mušāhada, breath control, murāqaba, iniciation.

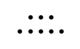

En las civilizaciones tradicionales, toda disciplina de estudio presupone un estrecho vínculo entre el maestro y el discípulo. La ciencia no se aprende en libros, pues estos sólo tienen una función subsidiaria y no pueden sustituir el rol de la transmisión oral de la enseñanza. El Islam tradicional siempre ha seguido esta regla, y aunque hoy en día incluso en la educación religiosa se han impuesto esquemas rígidos y programas específicos, todavía sobreviven aquí y allá métodos tradicionales en los que no se aprende una «asignatura», sino que se aprende un único texto de la voz viva de un maestro y se puede decir que lo ha entendido sólo una vez que éste ha emitido una licencia especial por escrito $(i \check{g} \bar{a} z a)$. La primera persona a quien 
se le concede la autoridad de poder explicar un libro es, obviamente, su autor, quien puede aclarar el significado de su escrito a sus discípulos, quienes, una vez obtenida la autorización necesaria, harán lo mismo con otros discípulos, y así sucesivamente hasta crear una verdadera «cadena» de enseñanza que garantice la continuidad de ese conocimiento particular en el tiempo.

Si esto es cierto para todas las ramas de las ciencias exotéricas, en el caso del esoterismo la relación entre el maestro y el alumno debe adquirir el carácter de un vínculo aún más profundo. De hecho, ya no se trata de impartir simples nociones, sino sobre todo de transmitir una influencia espiritual, que se transfiere del maestro al discípulo - por utilizar las palabras de un antiguo maestro sufí - «como una lámpara enciende otra lámpara» ${ }^{1}$, y se remonta así a través de las generaciones hasta llegar al magisterio espiritual del Profeta, entrelazándose de ese modo con lo que el sufismo llama la «cadena de oro» de la iniciación (silsilat al$\underline{d}(a h a b)^{2}$. La necesidad de reconectarse a una de estas «cadenas» se reitera continuamente en los tratados del esoterismo islámico, pues, según un famoso dicho, «quien no tiene maestro, tiene a Satanás por maestro».

La importancia atribuida al papel del maestro (šayh en árabe o pīr en persa) no hace sino confirmar una regla común a todas las tradiciones iniciáticas, que subrayan unánimemente la imposibilidad de obtener la más mínima realización sin recibir los medios de un guía autorizado a transmitirlos ${ }^{3}$. Ahora bien, es también admisible que en determinadas circunstancias la influencia espiritual puede ser transmitida por «entidades» de diversa índole y no por un

1 Cf. C. W. Ernst, Sufism. An Introduction to the Mystical Tradition of Islam, Boston-London, Shambala, 2011 , p. 124. El mismo concepto se expresa exactamente en los mismos términos en un texto tántrico śivaita, donde se dice que la línea espiritual se transmite «como de lámpara a lámpara» (Abhinavagupta, Luce delle sacre scritture [tantrāloka], editado por R. Gnoli, Turìn, UTET, 1972, p. 594). La imagen es además común en los escritos del tantrismo: «Como una lámpara se enciende con la llama de otra llama, así la Śakti divina contenida en el mantra, desde el cuerpo del Guru se comunica en el del discípulo» (J. Woodroffe, Śakti and Śakta, Essays and Addresses, Madras, Ganesh \& Co., 1959, p. 336.

2 La imagen de la «cadena» para describir este tipo de transmisión es común a varias tradiciones: cf. R. Guénon, Aperçus sur l'Initiation, París, Éditions Traditionnelles, 1946, p. 53.

3 Las referencias a este principio son innumerables; nos limitamos aquí a indicar sólo algunos ejemplos que se encuentran más fácilmente para cada una de las tradiciones iniciáticas. Para el sufismo: T. Burkhardt, Introdution aux doctrines ésotériques de l'Islam, Paris, Dervy Livres, 1969, p. 22; M. Valiuddin, Contemplative Discipline in Sufism, London-The Hague, East-West Publications, 1980, pp. 21-24; para el Yoga: M. Eliade, Lo Yoga. Immortalità e Libertà, Firenze, Sansoni, 1982, p. 21; para el budismo: S. B. Dasgupta, An Introduction to Tāntrik Buddhism, Calcutta, University of Calcutta, 1950, pp. 174-176; para el taoísmo: F. Pregadio, The Way of the Golden Elixir. An Introduction to Taoist Alchemy, Mountain View, Golden Elixir Press, 2014, p.3. 
maestro de carne y hueso ${ }^{4}$, pero se trata de episodios absolutamente excepcionales y que, en cualquier caso, muestran cómo resulta imposible prescindir de alguna forma de enseñanza iniciática, aunque esta se realice fuera de las vías ordinarias. La base de una transmisión iniciática correcta y regular, muchas veces fustigada por los espíritus modernos que solo ven en ello un fatigoso deber «notarial», no tiene en realidad nada de burocrático, sino que se basa en la observación elemental de que el discípulo debe necesariamente extraer de alguien que ya lo posee la influencia espiritual necesaria para que el método resulte operativo ${ }^{5}$. El hecho de que no se trata aquí de un mero formalismo administrativo es además evidente cuando se considera que el discípulo, al volver a conectarse con un maestro de la cadena, no sigue en absoluto una rigidez que le imponen las necesidades humanas, sino que responde en realidad a una disposición primigenia propia, porque «la persona del iniciador sólo puede ser reconocida por aquel cuyo espíritu ya había recibido la iluminación desde la preeternidad $»^{6}$. Resulta obvio, por lo tanto, que cualquier acto que desconozca estos principios fundamentales sólo puede producir una ilusión engañosa. Algunos maestros del sufismo persa dicen que el rito comunicado por un maestro es como una flecha sacada de la aljaba del rey, mientras que el de quien lo practica sin transmisión regular sería como una flecha comprada en el mercado: el arma seguiría siendo la misma, pero ¡qué diferencia en el objetivo que uno y otro tienen a la vista y en la protección que pueden proporcionar respectivamente en defensa del discípulo ${ }^{7}$ ! Otras formas de iniciación se expresan con idéntica claridad: «En la tradición hindú, el mantra que ha sido aprendido de cualquier otra manera que no sea por boca de un gurú autorizado no tiene ningún efecto, puesto que no ha sido "vivificado" por la presencia de la influencia espiritual de la que está destinado sólo a ser el vehículo» ${ }^{8}$. «Sin iniciación confirma el tantrismo -, la recitación (japa) del mantra, la adoración (püja) y los demás ritos son inútiles» ${ }^{9}$. Para utilizar la pintoresca expresión de un texto budista, «el practicante-yogui que pretende alcanzar la condición de yogui realizado sin la necesaria iniciación daría un puñetazo al cielo o bebería el agua de un espejismo» ${ }^{10}$.

4 Se trata de la iniciación obtenida «en espíritu» (rūhān $\vec{r}$ ), también llamada uwaysī por el nombre de Uways, un hombre que se convirtió en discípulo del Profeta Muhammad sin haberle conocido nunca en persona. Generalmente se dice que este tipo de iniciación es conferida por al-Hiḍr, el inmortal también mencionado en el Corán (sūra 18), que fue el guía de Moisés y que de vez en cuando hace su aparición entre los hombres para impartir sus instrucciones esotéricas.

5 Sobre el concepto de «regularidad iniciática», cf. R. Guénon, Aperçus sur l'Initiation, cit., pp. 39-48; Id, Initiation et Réalisation spirituelle, Paris, Éditions Traditionnelles, 1973, pp. 46-63.

6 H. Landolt, Estudio preliminar en N. Isfarâyinî, Le Révélateur des Mystéres, Lagrasse, Verdier, 1986, p. 54.

7 Cf. Ibid., p. 54.

8 R. Guénon, Aperçus sur l'Initiation, cit., p. 68.

9 J. Woodroffe, Śakti and Śakta, cit. p. 336.

10 S. B. Dasgupta, An Introduction to Tāntrik Buddhism, cit., p. 176. 
La «cadena de oro» se relata generalmente en una especie de diploma, que toda organización iniciática islámica debe poder exhibir como testimonio de su regularidad, indicando así en forma escrita todos los «eslabones» que reconectan al maestro actual con el Profeta Muhammad, generación tras generación. Se trata, pues, de un verdadero árbol genealógico ${ }^{11}$, que describe la filiación a través de la cual la enseñanza esotérica desciende desde su primer depositario. Cada rama de este árbol se considera una «Vía», tarīqa, es decir, una de las organizaciones iniciáticas que se han diferenciado de la misma raíz primordial.

$\mathrm{Al}$ confiarse al cuidado de un maestro, el discípulo no hace más que reconectarse con ese linaje, como si él mismo entrara en un pacto con la persona del Profeta. Se trata precisamente de la iniciación, que se define en términos de un «pacto» o «juramento» (bay'a) entre el aspirante y su instructor espiritual, según un procedimiento inspirado en el modelo del famoso «pacto de complacencia» (bay'at al-ridwān), que numerosos discípulos hicieron con el Profeta bajo los pies de un árbol en Hudaybiyya, una localidad cercana a La Meca ${ }^{12}$. En esa ocasión Muhammad pidió a todos los seguidores presentes que se unieran a él con un juramento solemne, juntando sus manos con las de él para sancionar el vínculo indisoluble que así se establecía. El Corán recuerda el episodio con estas palabras: «Los que te juran fidelidad juran fidelidad a Dios, y la mano de Dios está en sus manos. Quien viola el pacto lo viola en su propio perjuicio, y en cuanto a quien mantiene el pacto que ha hecho con Dios, tendrá una inmensa recompensa» ${ }^{13}$. El pacto con el Profeta es, por tanto, un pacto con Dios, y se define como «un pacto de satisfacción» porque Dios está tan complacido con él que promete una recompensa suprema a cambio, que consiste en el descenso de la paz interior (sakina) en los corazones. De hecho, el Corán añade poco después: «Dios se complació con los creyentes cuando te juraron fidelidad bajo el árbol, y sabía lo que había en sus corazones,

11 En el encabezamiento de estos diplomas iniciáticos encontramos a veces el propio término «árbol» (šağara) en lugar del más habitual «cadena» (silsila).

12 Sobre la asunción de este precedente histórico como prototipo del rito esotérico de iniciación, cf. P. Urizzi, Introducción a Kalābād̄ī, Il Sufismo nelle parole degli antichi, Palermo, Officina di Studi Medievali, 2002, p. 28. El hecho de que el término utilizado para indicar la iniciación, bay 'a, sea el mismo que el empleado para designar la investidura del califa confirma la analogía establecida en diversas tradiciones entre la transmisión iniciática y la consagración del poder temporal: así, en la India, la purificación llamada abhiseka suele acompañar al rito iniciático y denota al mismo tiempo la entronización del príncipe (cf. L. Silburn, La kundaliñ̄ o L'energia del profondo, Milano, Adelphi, 1997, p. 135 n. 2), y aún más estrecha es la relación entre la iniciación propiamente dicha y la unción del rey (räjasūya, cf. A.K. Coomaraswamy, Spiritual Authority and Temporal Power in the Indian Theory of Government, New Haven, American Oriental Society, 1942, pp. 8-10); una asimilación similar se observa también en los misterios clásicos, donde la expresión «asentado en el trono» ( $\left.\tau \varepsilon \square \rho o v ı \sigma \varepsilon^{\prime} v o \varsigma\right)$ se utiliza a menudo

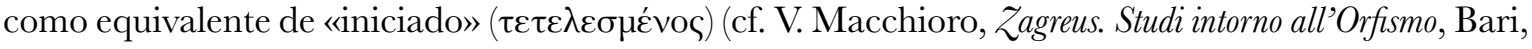
Laterza, 1920, p. 38).

13 Corán, 48:10. 
por lo que hizo descender sobre ellos Su presencia pacificadora y les recompensará con una victoria en poco tiempo»» ${ }^{14}$.

Con la celebración del rito de iniciación, el sufismo pretende, pues, reproducir ese acontecimiento lejano, y es por ello que toda iniciación en el Islam se confiere mediante el contacto entre las manos del maestro y las del discípulo. Es así como el aspirante asume el «vínculo» (nisba) característico de la tariqa que pretende seguir, es decir, recibe la influencia espiritual que a partir de entonces estará presente en él y que le permitirá progresar en la Vía en la medida de sus posibilidades. El maestro, por tanto, antes de aceptar al aspirante debe valorar cuáles son sus capacidades, que no dependen de una simple disposición de ánimo o de la expresión de una voluntad individual, sino que deben ser el reflejo de su naturaleza interior más profunda. La comprobación de estas cualificaciones, que un auténtico maestro identificar operar por sí solo sin ayuda de algún medio externo, suele ir acompañada de un rito especial, a través del cual el aspirante a discípulo será puesto a prueba de modo que pueda revelar sus verdaderas aptitudes. El rito consiste en la petición de una respuesta divina (istiḩâra), un procedimiento utilizado también en la vida religiosa ordinaria, pero que en el ámbito iniciático sirve precisamente para poner de manifiesto la compatibilidad de un ser con un determinado tipo de camino espiritual. Este procedimiento puede adoptar muchas formas diferentes - como, por ejemplo, observar la postura corporal del aspirante después de un determinado ejercicio, probarle en la ejecución de un gesto, proporcionarle sueños reveladores, leer los rasgos fisionómicos de la persona, etc. -, pero su finalidad sigue siendo, en todo caso, la de hacer evidente, mediante señales explícitas, que la tarīqa elegida es adecuada a las predisposiciones del postulante.

Cuando se produce la iniciación propiamente dicha, además del apretón de manos del que hemos hablado (y que es el elemento indispensable), se pueden prever otras formas rituales que, por así decirlo, rodean el aspecto esencial y contribuyen a aumentar su solemnidad a los ojos del discípulo ${ }^{15}$. Las oraciones, las fórmulas, los actos de devoción que el aspirante observa en esas circunstancias no son estrictamente necesarios, y de hecho pueden variar mucho según la organización iniciática, la orientación del maestro o el carácter del discípulo, por lo que los rituales nunca desembocan en formas absolutamente rígidos o en un mero formalismo. En cambio, las reglas que debe seguir el iniciado tras la conclusión del pacto están más definidas. El nuevo curso de vida que acaba de emprender le impone una serie

14 Corán, 48:18. Sobre la sakina, la presencia divina «apaciguadora» o «pacificadora» análoga a la shekinah judía, cf. A. Ventura, Sapienza sufi. Dottrine e simboli dell'esoterismo islamico, Roma, Edizioni Mediterranee, 2016, pp. 16, 220.

15 Para un ejemplo detallado, cf. C. W. Ernst, Sufism, cit., pp. 142-143; para una visión más general, cf. M. Chodkiewicz, «Note complémentaire sur les rites d'initiation dans les turuq», en 'Ayn al-Hayât, 5 (1999), pp. 45-64. 
de ejercicios preparatorios, que consisten sobre todo en la recitación diaria de diversas fórmulas o lecturas, según cantidades y tiempos preestablecidos que varían según el caso. Casi cada tarīqa tiene su propio ritual específico, cuyos elementos más significativos están representados por el wird, una serie de jaculatorias que se repiten cientos o incluso miles de veces en determinados momentos del día, y por el hizb, un texto más articulado que se lee periódicamente, que se considera el patrimonio distintivo de esa tarīqa y que contiene significados simbólicos y esotéricos de especial importancia.

\section{LA EFICAGIA DEL DIKR, LA MENGIÓN DE LOS NOMBRES DIVINOS, EN LA REALIZAGIÓN ESPIRITUAL SUFÍ}

Todo esto entra, sin embargo, en el ámbito de lo que podríamos llamar los «soportes» más externos, es decir, los actos destinados a preparar al discípulo para el trabajo puramente interior al que se enfrentará más tarde y para el que sólo existe un medio realmente eficaz, utilizado sin excepción en todas las prácticas sufies: el $\underline{d i k r}$. El término significa al mismo tiempo «recuerdo» y «mención», por lo que es especialmente apropiado para definir ese proceso «mnemónico» que permite, gracias a la repetición continua de los Nombres Divinos, poner freno al «olvido» provocado por la existencia fenoménica y, de ese modo, encontrar la realidad más profunda del propio ser.

En diversos pasajes del Corán se recomienda el recuerdo de Dios, o la mención de Sus Nombres, mencionemos algunos ejemplos: «El recuerdo de Dios es lo más grande» ${ }^{16}$; «Invócale por el nombre Allāh, o invócale por el nombre el Clemente, sea como sea que le llames los mejores nombres le pertenecen» ${ }^{17}$; «Recuerda el nombre de tu Señor, abandónate enteramente a Él»» ${ }^{18}$; «Acuérdate de mí y yo me acordaré de ti» ${ }^{19}$; «نNo es en el recuerdo de Dios donde se apaciguan los corazones? $\gg^{20}$. Ni siquiera las preocupaciones de la vida deben distraernos de este ejercicio fundamental: «En las casas que Dios ha permitido construir, y en las que se recuerda su nombre, que los hombres le den gloria al amanecer y al atardecer, que ningún comercio, ninguna venta, sustraiga al recuerdo del nombre de Dios» ${ }^{21}$. Se dice que uno de los compañeros del Profeta, Ibn 'Abbās, comentó a este respecto: «Dios no ha decretado obligatorio ningún acto de adoración para Sus siervos sin ponerle un límite e

16 Corán, 29:45.

17 Corán, 17:110.

18 Corán, 73:8.

19 Corán, 2:152.

20 Corán, 13:28.

21 Corán, 24:36-37. 
incluso ha eximido de él a quienes tengan justificación. Pero el $\underline{d i k r}$, el recuerdo, es una adoración tal que Dios no le ha puesto límite, ni ha eximido a nadie de hacerlo, excepto a los enfermos mentales, recomendando a todos que Le recuerden en cualquier condición» ${ }^{22}$. Un comportamiento contrario a estos preceptos supondría incurrir en el «olvido» (nas̄̄o ghafla), que no debe entenderse como una simple negligencia, sino como la causa de una completa perdición, pues - siempre es el Corán el que lo afirma - «A los que se desvíen de la memoria del Clemente les daremos por compañero un demonio, que le estorbará en el camino mientras él se engañará a sí mismo diciendo que está bien guiado» ${ }^{23}$; y de nuevo: «Y no seáis como los que se olvidaron de Dios y a los que Dios hizo olvidar, he aquí los malvados» ${ }^{24}$.

En el ámbito del exoterismo religioso, estas advertencias se entienden como una invitación a recordar a Dios lo más posible en cada momento de la vida, sin embargo para quienes pretenden seguir la vía del esoterismo, el dikr representa un verdadero compromiso ritual. No se trata sólo de tener presente la existencia de Dios, sino de invocar insistentemente $\mathrm{Su}$ Nombre, con un ejercicio similar al japa, la repetición del mantra en el método del Yoga. La invocación debe realizarse con la mayor continuidad posible y según reglas precisas, para que la presencia divina en uno mismo se convierta en un acto constante y natural, casi como una operación fisiológica independiente de la voluntad y realizada sin ningún esfuerzo. De hecho, se dice que el mero acto de respirar ya representa una forma de $\underline{d i k r}$, ya que el más «íntimo» entre los Nombres divinos es precisamente la letra $h \bar{a}$, que se pronuncia como una $h$ ligeramente aspirada ${ }^{25}$. De este modo, todos los seres vivos, con la simple exhalación de la respiración, «recuerdan» a Dios en cada momento, aunque para la mayoría esto ocurra de manera inconsciente: la tarea del $\underline{d i k r}$ iniciático será precisamente hacer de ese recuerdo un acto plenamente consciente, pues sólo con una conciencia tal se puede dar continuidad a la presencia interior (hudūr) en cualquier situación en la que se encuentre. Una vez que se

22 M. Valiuddin, Contemplative Disciplines in Sufism, cit., p. 32.

23 Corán, 43:36-37.

24 Corán, 59:19-20.

25 Para la conexión entre el dikr y el aliento común, cf. Najm al-dīn Kubrā, Gli schiudimenti della bellezza e i profumi della maestà. Fawātị al-jamāl wa fawā’ḥ al-jalāl, editado por N. Norozi, Mimesis, Milano-Udine 2011, pp. 53, 156-157; A. Ventura, Sapienza sufi, cit., p. 52. Podemos encontrar un concepto idéntico en el hinduismo, que considera la respiración como una forma superior de mantra, llamado ajapa («no pronunciado») porque se realiza de forma natural y sin ningún esfuerzo (cf. J. Woodroffe, Śakti and Śakta, cit., p. 291; Id., The Serpent Power, Madras, Ganesh \& Co., 1950, p. 76; Id., The Garland of Letters. Studies in the Mantra-Śāstra, Madras, Ganesh \& Co., 1974, p. 278). La analogía entre el ajapā hindú y la idea islámica de una invocación natural realizada con el simple aliento está claramente expuesta en Muhammad Dārā Šikōh, La congiunzione dei due oceani, editado por S. D’Onofrio y F. Speziale, Adelphi, Milano 2011, pp. 85-86. 
logra tal constancia, se puede apreciar realmente el significado de las palabras atribuidas al Profeta: «Mis ojos duermen, pero mi corazón no».

El $\underline{d} i k r$ debe ser comunicado por el maestro mediante un procedimiento llamado talqin, $\mathrm{y}$ esto ocurre a veces en el mismo momento de la iniciación, mientras que en otros casos la transmisión se pospone a un momento posterior, cuando se considera que el discípulo está preparado para afrontar efectivamente la práctica. El instructor indicará entonces las palabras exactas que deben utilizarse, en qué cantidad y en qué momentos del día deben decirse, así como el ritmo y la cadencia de la repetición. La concentración absoluta es, por supuesto, necesaria en el curso del ejercicio para que los pensamientos no distraigan al iniciado de su objetivo y, de hecho, existen diversos métodos que permiten ayudar a la mente fijar su atención en un punto (posiciones del cuerpo, ajustes de la respiración, imágenes a visualizar). La concentración y la atención en los procesos mentales se consideran en cualquier forma iniciática requisitos indispensables, puesto que son precisamente las corrientes de pensamiento siempre cambiantes las que favorecen la dispersión del ser en la multiplicidad fenoménica y dificultan la visión de la realidad interior ${ }^{26}$.

En cuanto a la forma del $\underline{d i k r}$, consiste en la pronunciación de un Nombre divino o de una fórmula que lo contenga ${ }^{27}$. Las expresiones más utilizadas son el «nombre proprio» de Dios, Allāh y, muy particularmente, la profesión de fe musulmana, «no hay más deidad que Dios», $l \bar{a}$ ilāha illä Allāh; pero también se recurre a menudo a otros apelativos tradicionales de la deidad - como, por ejemplo, «el Viviente» (al-Hayy), «el Subsistente» (al-Qayyūm), «el Conocedor» (al-'Alīm), «el Precioso» (al-'Azīz), etc. - y a veces a sonidos aún más concentrados, como Hū, que alude al pronombre «Él», o a simples emisiones de la respiración, como $h$ o $h \bar{a}$, que ya hemos visto que representan la denominación más íntima y «secreta» de Dios. En cualquier caso, la eficacia de estas palabras no consiste en la mera secuencia de sus letras, que en sí misma no produce ningún efecto real, sino en el espíritu que les ha infundido el maestro, en el ritmo con que se pronuncian, en la aplicación de la persona que las pronuncia ${ }^{28}$. En esto, podemos constatar una vez más que el $\underline{d i k r}$ es un equivalente exacto del mantra, es decir, esa «aspiración del ser hacia lo universal» capaz de producir «vibraciones rítmicas que repercuten a través de un campo más o menos extendido en la serie indefinida de estados del ser» ${ }^{29}$. Es como si el $\underline{d i k r}$ - dice un maestro sufí de la India para simbolizar esta propagaciónencendiera una llama de luz (šu la-yi nūr) en los espíritus de los ángeles inferiores, y luego, con

26 Sobre la vigilancia de los pensamientos en la doctrina del esoterismo islámico, cf. A. Ventura, Sapienza sufi, cit., capítulo III.

27 Para una visión general del uso de los Nombres Divinos, cf. C. W. Ernst, Sufism, cit., pp. 81-98. 28 «Para conseguir el efecto deseado» - afirma el tantrismo - «el mantra debe entonarse correctamente, tanto según el sonido (varna) como según el ritmo (svara)» (J. Woodroffe, Śakti and Śakta, cit., p. 385).

29 R. Guénon, Aperçus sur l'Initiation, cit. pp. 169-170. 
la intensificación de la recitación, la llama se transmitiera a los ángeles superiores, y luego de nuevo hasta el dominio trascendente, donde la llama va a fijarse en esa epifanía divina que habita en el corazón del «Gran Hombre» (šahș-i akbar), es decir, del ser humano plenamente realizado, o universal ${ }^{30}$. En otros casos, el efecto de la invocación se describe como una «llama ascendente y pura» ${ }^{31}$, y un maestro recuerda que, desde sus primeras manifestaciones, el $\underline{d i k r}$ hacía surgir del lado izquierdo de su pecho (por tanto, en correspondencia con el corazón) una serie de chispas luminosas, que vibraban hacia el cielo y finalmente lo penetraban ${ }^{32}$.

\section{RESPIRAGIÓN, VIBRAGIÓN E INVOGAGIÓN COMO PRELUDIOS DE LA TOTALIZAGIÓN DEL SER}

Para que el $\underline{d i k r}$ provoque este tipo de vibraciones y no sea una simple emisión de sonidos, se atribuye gran importancia al ritmo con el que debe formularse. Los textos islámicos insisten con frecuencia en la necesidad de seguir cadencias precisas durante la recitación, a fin de articular el sonido según un determinado número de tiempos de ritmo regular. El concepto de «bateo» (darb), que debe entenderse como una ascensión a través de la pronunciación de las fórmulas, lo que permite al iniciado obtener la inflexión más eficaz mediante una modulación a intervalos definidos ${ }^{33}$. La frecuencia puede variar según el tipo de invocación elegida, y se puede hacer $\underline{d i k r}$ en diferentes tiempos, siendo el más utilizado el que generalmente se incluye en un arco que va de uno a cuatro. Además del ritmo, también se presta mucha atención a la calidad de la voz (sawt), porque la emisión del sonido debe expresar una naturaleza diferente a la de la acústica ordinaria y acceder a instrumentos vocales más profundos y sutiles, que desde la lengua suben a las fuentes de la garganta, el corazón y el ombligo. Esta progresiva interiorización de la voz tiene como fin último, en su forma más sublimada, la pronunciación puramente silenciosa del $\underline{d} h i k r$, al igual que en el Yoga se parte de la repetición verbal (vāaikajapa), pasando luego a una articulación apenas insinuada con los labios (upāmśu-japa) para finalizar con la recitación únicamente mental (mānasa-japa $)^{34}$.

30 Cf. Šāh Walī Allāh, Hama ‘̄at, Hyderabad, Akādimiya al-Šāh Wal̄̄ Allāh al-Dihlawī, 1964, p. 51.

31 Najm al-dīn Kubrā, Gli schiudimenti della bellezza e i profumi della maestà, cit., p. 83.

32 Cf. G. M. Martini, Alā' al-Dawla al-Simnān̄ between Spiritual Authority and Political Power. A Persian Lord and Intellectual in the Heart of the Ilkhanate, Leiden-Boston, Brill, 2017, p. 42.

33 Sobre la descripción de las diferentes formas de «bateo», cf. C. W. Ernst, Sufism, cit., p. 109; H. Landolt, Estudio preliminar en N. Isfarâyinî, Le Révélateur des Mystéres, cit., pp. 45-48; S. Kugle (ed.), Sufi Meditation and Contemplation. Timeless Wisdom from Mughal India, Omega Publications-Suluk Press, New Lebanon 2012, pp. 57-61, 66; M. Valiuddin, Contemplative Disciplines in Sufism, cit., pp. 52, 72 n. 2, 78-80. 34 Cf. A. Avalon, Śakti and Śakta, cit., pp. 358, 376, 437. 
La eficacia del $\underline{d i k r}$ aumenta con la disciplina de la respiración, que debe ser tal que acompañe al ritmo de forma homogénea, evitando las irregularidades y discontinuidades que suelen caracterizar la respiración habitual. Además, por analogía con el Yoga, la suspensión o contracción de la respiración es extremadamente útil para favorecer la concentración y fijar mejor el objetivo de la práctica, aunque no todas las organizaciones iniciáticas consideren obligatorio su uso. La práctica de la suspensión de la respiración (habs al-nafas) se realiza de dos maneras diferentes: por vaciado (tahliyya), que se hace contrayendo el abdomen y haciendo subir el aire que contiene para retenerlo en el pecho o en el cerebro; o por llenado (tamliyya), que consiste en empujar hacia abajo el aire retenido saturando el abdomen. La contracción de la respiración (hașr al-nafas) consiste, en cambio, en una disminución progresiva del proceso respiratorio, que se obtiene acortando cada vez más las fases de inhalación y exhalación ${ }^{35}$.

Una disciplina cuidadosa de las posiciones del cuerpo puede ayudar a la concentración. Para facilitar el proceso meditativo, se recomienda asumir durante el ritual una postura erguida del tronco, lo suficientemente cómoda como para evitar esfuerzos excesivos, pero no tan relajada como para provocar somnolencia. Generalmente, teniendo en cuenta los hábitos rituales islámicos, la posición que se sugiere como más adecuada es similar a la que el Yoga define como vajrāsana, es decir, sentado sobre las piernas dobladas, con las manos sobre las rodillas y el torso erguido, preferiblemente mirando en dirección a la Meca (como en una de las fases de la oración canónica); pero en otros casos también se recomienda sentarse con las piernas cruzadas, porque permite realizar un $\underline{d} i k r$ más «vigoroso» ${ }^{36}$. A veces el $\underline{d i k r}$ puede incluir movimientos de acompañamiento, pero también en este caso cada gesto debe estar perfectamente regulado y seguir la cadencia de la invocación, evitando cualquier movimiento inconexo y desordenado. El objetivo más inmediato de todas estas prácticas es básicamente el mismo que Mircea Eliade identificó con respecto al Yoga, es decir, inducir una actitud lo más alejada posible de los hábitos normales: modular los ritmos de la pronunciación, recurrir a formas vocales más interiores, gobernar y regular la respiración, detener los movimientos incontrolados del cuerpo, todo ello significa suprimir y superar los mecanismos desordenados de la existencia ordinaria, que impiden la unificación y la totalización del $\operatorname{ser}^{37}$.

Los aspectos del rito esotérico que hemos examinado hasta ahora se refieren al trabajo estrictamente personal del discípulo, que es la razón de ser de toda Vía iniciática. Además y como apoyo a esta vía, que generalmente se realiza en un lugar apartado, en silencio y con los ojos cerrados, puede haber también momentos de participación colectiva, durante los cuales los discípulos de una tarīqa se reúnen para realizar un $\underline{d i k r}$ coral. Bajo la dirección del maestro

35 Cf. S. Kugle (ed.), Sufi Meditation and Contemplation, cit., p. 45; M. Valiuddin, Contemplative Disciplines in Sufism, cit., p. 83.

36 Cf. H. Landolt, Estudio preliminar en N. Isfarâyinî, Le Révélateur des Mystéres, cit., p. 43.

37 Cf. M. Eliade, Lo Yoga, cit., p. 63-64. 
o de su delegado, los iniciados se disponen en círculo y comienzan a pronunciar invocaciones rítmicas y cada vez más aceleradas, a menudo cogidos de la mano y acompañándose con gestos corporales como movimientos de cabeza, balanceos, saltos, etc. La mayoría de las veces, este rito colectivo está acompañado por cantantes (munšidūn), que entonan himnos o poemas sufies con ritmo creciente, con un trasfondo de instrumentos de percusión, útiles para marcar el tiempo de los compases. En sus formas más elaboradas, el acompañamiento se realiza también con otros instrumentos musicales, que constituyen la base de una danza más articulada y llena de significados simbólicos (como la de los famosos «derviches giratorios» de Konya). El rito, que se realiza en las mezquitas o en habitaciones privadas desde la antigüedad, se denomina la «audición» $\left(s a m \bar{a}^{\bullet}\right)$ - también llamada hadra entre los árabes y qawrwāli en la India -, una especie de concierto espiritual gracias al cual aumenta el entusiasmo de los practicantes y se cimienta la unión entre los hermanos. Condenado por los rigoristas y por algunos doctores de la ley como una forma de exaltación embriagadora y excesivamente sensual, el sama $\bar{a}^{\varsigma}$ ha sido generalmente aceptado por los sufies, que, por el contrario, lo ven como una práctica legítima siempre que no asuma formas demasiado exuberantes ${ }^{38}$.

El carácter espectacular de estos ritos colectivos siempre ha atraído la atención de los observadores profanos, lo que explica que el concierto espiritual sea quizá la única práctica sufí que ha obtenido cierta popularidad también en Occidente, donde a menudo se ha confundido con el aspecto más cualificado del sufismo. No debemos olvidar, sin embargo, que el $\underline{d i k r}$ colectivo es una forma ritual totalmente incidental y relativamente externa, que por ningún motivo podría sustituir la práctica individual de cada discípulo, que debe realizarse necesariamente de manera aislada. Incluso si juzgáramos con demasiada dureza el juicio de algunos maestros, para quienes el $s a m \bar{a}^{6}$ es un solo instrumento que permite auxiliar a los espíritus menos agudos, el hecho es que tiene la naturaleza de un mero soporte formal, y como tal no puede ser considerado ciertamente como el verdadero fundamento del método. Esto se confirma por el hecho de que algunas Vías Sufies no contemplan su uso, contándolo entre aquellos medios que, aunque legítimos, no son en absoluto indispensables para la realización efectiva.

Mucho más esencial, por el contrario, es un método que a menudo se considera más eficaz que el propio $\underline{d i k r}$, a saber, la pura contemplación ${ }^{39}$. La invocación y la contemplación no son

38 Cf. M. Molé, «La Danse extatique en Islam», en Les Danses sacrées (Sources Orientales VI), Paris, Seuil, 1963, pp. 147-279; al-Ghazâlî, Il concerto mistico e l'estasi, editado por A. Iacovella, Turín, Il Leone Verde, 1999.

39 Sobre los diferentes métodos de invocación y contemplación, cf. M. Valiuddin, Contemplative Disciplines in Sufism, cit.; M. I. Waley, «Contemplative Disciplines in Early Persian Sufism», en L. Lewisohn (ed.), Classical Persian Sufism from its Origins to Rumi (700-1300), vol. I, Oxford, Oneworld Publications, 1999, pp. 497-548. 
incompatibles y pueden combinarse de diversas maneras, pero la disciplina contemplativa proporciona un acceso más directo e inmediato a la realidad espiritual. Es el caso de las diversas formas de «visión» - como la mušāhada, el šuhüd, el $i^{6} y \bar{a} n$ - que toman como soporte cualquier objeto manifestado, una imagen, una forma humana, para remontarse a través de la meditación a la Realidad que ella expresa de forma simbólica. La atención enfocada hacia la belleza humana y poder reconocer en ella la Belleza divina es un ejemplo típico de este tipo de contemplación, como nos muestra la doctrina magistralmente expresada por Rūzbehān Baqlī y todos los demás «Fieles de Amor» de la poesía árabe y persa ${ }^{40}$. Pero hay otra forma de contemplación que no se sirve de soportes materiales, sino que consiste exclusivamente en la reflexión intelectual. Así lo expresa el árabe murāqaba, palabra cuya raíz etimológica $(r-q-b)$ expresa el sentido de contemplar, observar o esperar. Frente a los otros términos mencionados, que siempre podemos traducir como «contemplación», pero que implican sobre todo una idea de «visión», murāqaba pretende indicar más bien una atención totalmente centrada en el objetivo, similar a la espera inmóvil de un gato que observa a su presa $^{41}$.

Esta contemplación exclusivamente intelectual logra su propósito mediante una reflexión (ta'ammul) centrada en realidades metafísicas desprovistas de toda forma, que de alguna manera se captan directamente y sin ningún soporte concreto. Es por ello que ciertos textos sufies de la India, para facilitar este proceso, evitan centrar su atención en dibujos o estructuras geométricas complejas (como mandala o yantra), sino que sugieren utilizar simples círculos vacíos, sólo para reducir al mínimo todas las apariencias externas e inducir una meditación que no resulte condicionada por forma alguna. Entre las figuras geométricas, el círculo es, de hecho, el que posee la mayor indeterminación posible: «Las estaciones que conducen a la proximidad con lo divino se describen como círculos (dawä’ir) porque estas formas circulares están vacías, sin lados ni direcciones, no tienen ni arriba ni abajo, ni derecha ni izquierda, ni principio ni fin, siendo el preludio final a la esencia divina, pues allí ¿qué círculo podría representar a Dios?» ${ }^{42}$

Traducción del italiano por Armando Montoya Jordán.

40 Para un análisis detallado de este aspecto, cf. H. Corbin, «Rûzbehân Baqlî Shîrâzî (522/1128606/1209) et le Soufisme del Fidèles d'Amour», en En Islam iranien, Paris, Gallimard, 1972, vol. III, pp. 7-146.

41 Esta imagen es muy frecuente en los textos sufies.

42 Cf. A. Ventura, Lo Yoga dell'Islam, Roma, Edizioni Mediterranee, 2019, p. 100. 